\title{
Oscillation Symmetry Applied to Nuclear Level Widths and Masses
}

\author{
B. Tatischeff \\ CNRS/IN2P3, Institut de Physique Nucléaire, UMR 8608, Orsay, F-91405 \\ and Univ. Paris-Sud, Orsay, F-91405, France \\ Email: tati@ipno.in2p3.fr
}

\begin{abstract}
A systematic study of hadronic masses shows regular oscillations observed when the difference between adjacent masses of each family is plotted versus the mean mass. This symmetry of oscillation is even better observed for the nuclear level masses and nuclear level widths of given spins. The variation of nuclear level widths is studied and is compared to the variation of nuclear level masses. Such given spin variations, following an oscillatory symmetry, show that there is a correlation between the variation of masses and widths of nuclear excited levels.
\end{abstract}

Keywords: Nuclear masses, widths, symmetry, oscillations

\section{Introduction}

A new property of hadronic and atomic masses was recently shown [1], namely that they obey to regular oscillations, fitted by simple cosine functions. Such property appears afterwards legitimate, since these bodies result from different smaller bodies (quarks and nucleons) which are subjected to at least two different interactions, one attractive and one repulsive.

This property was checked on meson and baryon masses, as well as on many nuclei masses. Since the masses result from the Schrödinger equations, such observation could be anticipated. On another side, the widths of all these masses do not arise simply from the Schrödinger equations.

The present work is devoted to studying the widths of the nuclei excited states, in order to question whether their values still follow the oscillatory property. The data are taken from the litterature and fitted with the function:

$$
\Delta M=\alpha_{0}+\alpha_{1} \cos \left(\left(M-M_{0}\right) / M_{1}\right)
$$

where $\mathrm{M}_{0} / \mathrm{M}_{1}$ is defined within $2 \pi$. The oscillation periods, $\mathrm{P}=2 \pi M_{1}$ are studied. The amplitude of oscillations deserves theoretical studies which are outside the scope of the present work. We select the nuclei having at least five excited levels with known spin and known width.

\section{$2 \quad$ Study of Nuclear Level Widths}

It was shown that very nice fits were obtained for masses of nuclei excited states, provided they are studied for given spins [2]. The following figures show the widths of the nuclei excited states for given spins. The large scale of widths requires to draw them in log scale.

Fig. 1 shows the data and fits for ${ }^{8} \mathrm{Be} J=2$ in insert (a) [3] and for ${ }^{14} \mathrm{~N}$ in insert (b) [4]. We observe that the data are very well fitted with oscillations, with respectively periods of $\mathrm{P}=4.4 \mathrm{MeV}$ and $\mathrm{P}=1.13 \mathrm{MeV}$. The fits agree with the data, in spite of the fact that the data are scattered by more than four orders of magnitude.

Fig. 2 shows the data and fits for the widths of the excited states of the ${ }^{10} \mathrm{~B}$ nucleus [3]. $\mathrm{J}=1$ in insert (a) fitted by oscillations with $\mathrm{P}=1.16 \mathrm{MeV}$ and $\mathrm{J}=2$ in insert (b) fitted by oscillations with $\mathrm{P}=0.817 \mathrm{MeV}$. The widths of the two first levels in insert (a) are too small, by several order of magnitude, and are consequently not plotted in fig. 2. This is also the case for the first data in insert (b).

Fig. 3 shows the data and fits for the widths of the excited states of the ${ }^{13} \mathrm{C}$ nucleus [4]. $\mathrm{J}=3 / 2$ in insert (a) fitted by oscillations with $\mathrm{P}=1.13 \mathrm{MeV}$ and $\mathrm{J}=5 / 2$ in insert (b) fitted by oscillations with 

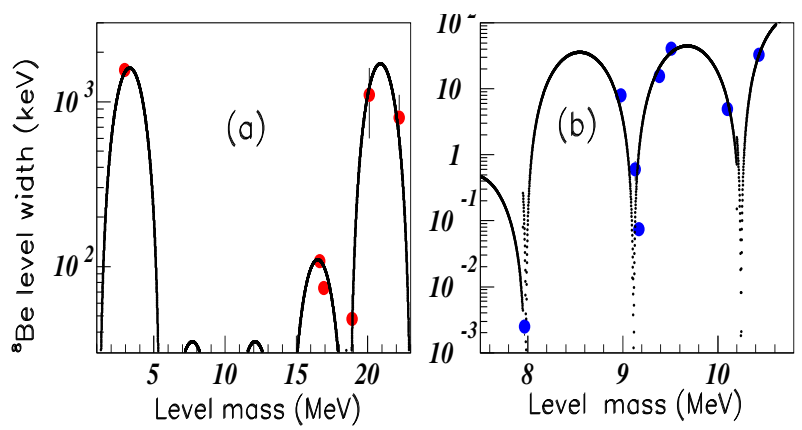

Figure 1. Color on line. Insert (a) shows for ${ }^{8} \mathrm{Be}$, the widths of the $\mathrm{J}=2$ excited levels, plotted versus their masses. Insert (b) shows the same for ${ }^{14} \mathrm{~N}$ nuclei. See text.
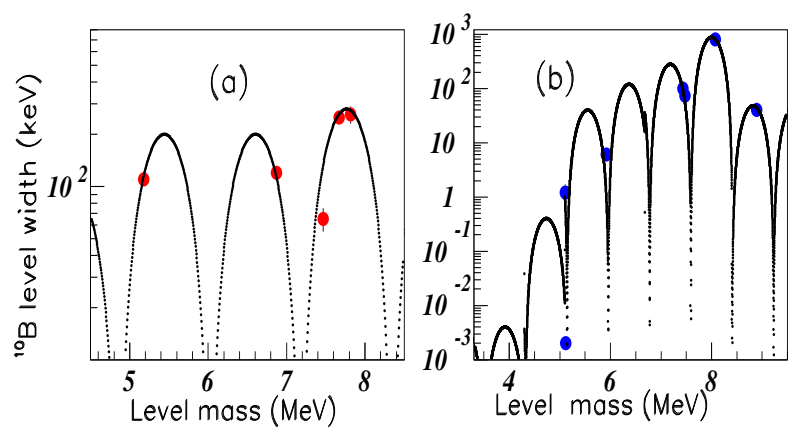

Figure 2. Color on line. Inserts (a) and (b) show the data and fits for the widths of the excited states of the ${ }^{10} \mathrm{~B}$ nucleus, $\mathrm{J}=1$ and $\mathrm{J}=2$ respectively. See text.

$\mathrm{P}=0.817 \mathrm{MeV}$. The fits here also, agree with the data, in spite of the fact that the data are scattered within more than two orders of magnitude.

Fig. 4 shows the data and fits for the widths of the excited states of the ${ }^{13} \mathrm{~N}$ nucleus [4]. $\mathrm{J}=3 / 2$ in insert (a) fitted by oscillations with $\mathrm{P}=1.16 \mathrm{MeV}$ and $\mathrm{J}=5 / 2$ in insert (b) $\mathrm{P}=0.817 \mathrm{MeV}$.

The excited state masses in both $\mathrm{A}=13$ isobar nuclei are not the same, as seen in page 55 of [4]. However the periods are quite the same for these two nuclei of $\mathrm{A}=13$ atomic mass number. The periods of $\mathrm{J}=3 / 2$, then $\mathrm{J}=5 / 2$ for ${ }^{13} \mathrm{C}$ nucleus are close to those found previously for $\mathrm{J}=1$ then $\mathrm{J}=2{ }^{10} \mathrm{~B}$ nucleus, and for $\mathrm{J}=2^{14} \mathrm{~N}$.

Fig. 5 shows the data and fits for the widths of the excited states of the ${ }^{15} \mathrm{O}$ nucleus [4]. $\mathrm{J}=1 / 2$ in insert (a) fitted by oscillations with $\mathrm{P}=1.82 \mathrm{MeV}, \mathrm{J}=3 / 2$ in insert (b) fitted by oscillations with $\mathrm{P}=1.13 \mathrm{MeV}$, and $\mathrm{J}=5 / 2$ in insert (c) fitted by oscillations with $\mathrm{P}=0.69 \mathrm{MeV}$ where there is one data (among ten) outside the fit.

Fig. 6 shows the data and fits for the widths of the excited states of the ${ }^{16} \mathrm{~N}$ nucleus [5]. Data for $\mathrm{J}=1$ in insert (a) are fitted by oscillations with $\mathrm{P}=3.016 \mathrm{MeV}$. Data for $\mathrm{J}=2$ are fitted by oscillations with $\mathrm{P}=2.765$.

Fig. 7 shows the data and fits for the widths of the excited states of the ${ }^{16} \mathrm{O}$ nucleus [5]. Inserts (a), (b), (c), (d), and (e) show data and fits for $\mathrm{J}=0 \mathrm{P}=4.4 \mathrm{MeV}, \mathrm{J}=1 \mathrm{P}=1.51 \mathrm{MeV}, \mathrm{J}=2 \mathrm{P}=1.13 \mathrm{MeV}, \mathrm{J}=3$ $\mathrm{P}=2.01 \mathrm{MeV}$, and $\mathrm{J}=4 \mathrm{P}=1.26 \mathrm{MeV}$ respectively.

Fig. 8 shows data and fits for the widths of the excited states of the ${ }^{21} \mathrm{Ne}$ nucleus $\mathrm{J}=3 / 2[6]$ in insert (a), and data and fits for ${ }^{24} \mathrm{Mg}$ [6] in inserts (b), (c), and (d) for $\mathrm{J}=0,1$, and 2 respectively. The periods of the four inserts (a), (b), (c), and (d) are respectively $\mathrm{P}=0.49 \mathrm{MeV}, \mathrm{P}=0.942 \mathrm{MeV}, \mathrm{P}=0.628 \mathrm{MeV}$, and $\mathrm{P}=0.44 \mathrm{MeV}$.

Fig. 9 shows data [6] and fits for the widths of the excited states of the ${ }^{25} \mathrm{Mg}$ nucleus $\mathrm{J}=1 / 2$ in insert (a), $\mathrm{P}=0.496 \mathrm{MeV}$ and $\mathrm{J}=3 / 2$ in insert (b), $\mathrm{P}=0.377 \mathrm{MeV}$. 


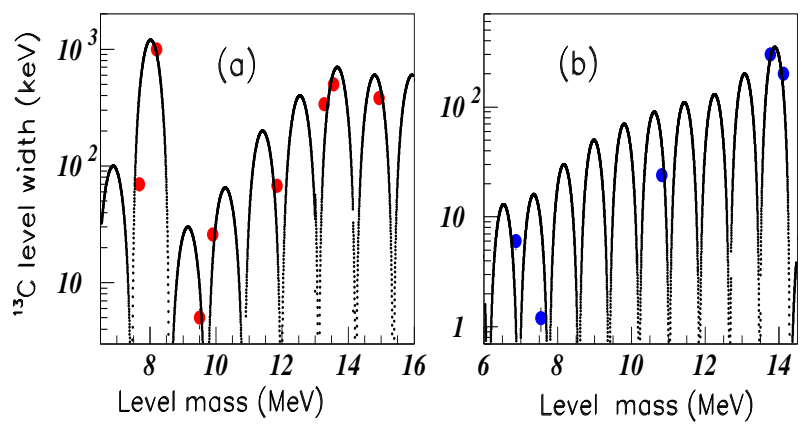

Figure 3. Color on line. Data and fits for ${ }^{13} \mathrm{C}$ nucleus excited state level widths. $\mathrm{J}=3 / 2$ in insert (a) and $\mathrm{J}=5 / 2$ in insert (b). See text.
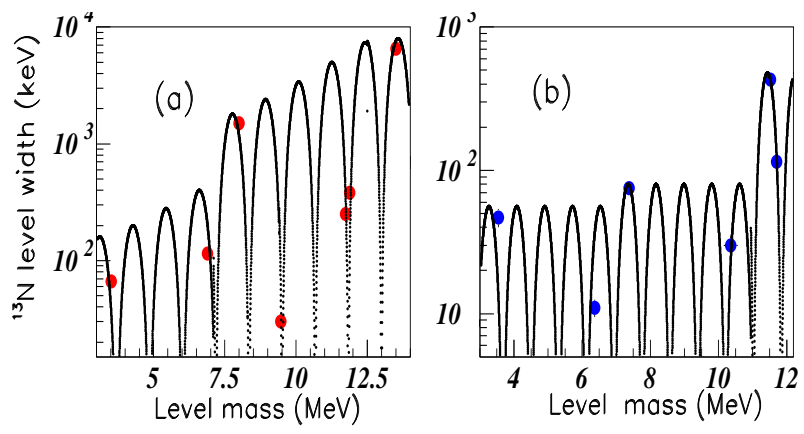

Figure 4. Color on line. Data and fits for ${ }^{13} \mathrm{~N}$ nucleus excited state level widths $\mathrm{J}=3 / 2$ in insert (a) and $\mathrm{J}=5 / 2$ in insert (b). See text.

Fig. 10 shows data [6] and fits for the widths of the excited states of the ${ }^{43} \mathrm{Sc}$ nucleus (red circles) excited $\mathrm{J}=3 / 2$ in insert (a), $\mathrm{P}=0.484 \mathrm{MeV}$ and $\mathrm{J}=5 / 2$ in insert (b), $\mathrm{P}=0.484 \mathrm{MeV}$. Blue full circles correspond to ${ }^{43} \mathrm{Ca}$ nucleus. The fit for ${ }^{43} \mathrm{Ca}$ may be improved by a little curve translation by $\Delta \mathrm{M}=-$ $0.12 \mathrm{MeV}$ (with the same period).

Fig. 11 shows data $[6]$ and fits for the widths of the excited states of the ${ }^{40} \mathrm{Ca}$ nucleus $\mathrm{J}=2$ in insert (a) $\mathrm{P}=0.484$, and $\mathrm{J}=4$ in insert (b) $\mathrm{P}=0.49$. Data and fits for the widths of the excited states of the ${ }^{34} \mathrm{Cl}$ nucleus are shown for $\mathrm{J}=1$ in insert (c) $\mathrm{P}=0.534$, and $\mathrm{J}=2$ in insert (d) $\mathrm{P}=0.547$.

Fig. 12 shows data [6] and fits for ${ }^{41} \mathrm{Ca}$ nucleus (in red) and ${ }^{41} \mathrm{Sc}$ nucleus (in blue). $\mathrm{P}=0.484 \mathrm{MeV}$ for $\mathrm{J}=1 / 2$ levels (insert (a)), $\mathrm{P}=0.49 \mathrm{MeV}$ for $\mathrm{J}=3 / 2$ levels (insert (b)), and $\mathrm{P}=1.50 \mathrm{MeV}$ for $\mathrm{J}=5 / 2$ levels (insert (c)). The amplitude of oscillations are larger for ${ }^{41} \mathrm{Sc}$ nucleus than for ${ }^{41} \mathrm{Ca}$, but the periods are the same and there is no mass shift.

Fig. 13 shows data [7] and fits for the widths of the excited states of the ${ }^{208} \mathrm{~Pb}$ nuclei. Inserts (a), (b), (c), and (d) correspond respectively to $\mathrm{J}=3 \mathrm{P}=0.82 \mathrm{MeV}, \mathrm{J}=4 \mathrm{P}=0.82 \mathrm{MeV}, \mathrm{J}=5 \mathrm{P}=0.66 \mathrm{MeV}$, and $\mathrm{J}=6$ $\mathrm{P}=0.48 \mathrm{MeV}$.

Fig. 14 shows data [6] and fits for the widths of the excited states of the ${ }^{17} \mathrm{O}$ (blue stars on line) and ${ }^{17} \mathrm{~F}$ (red circles on line) nuclei. Inserts (a), (b), (c), and (d) correspond respectively to $\mathrm{J}=1 / 2 \mathrm{P}=1.01 \mathrm{MeV}$, $\mathrm{J}=3 / 2 \mathrm{P}=0.88 \mathrm{MeV}, \mathrm{J}=5 / 2 \mathrm{P}=0.817 \mathrm{MeV}$, and $\mathrm{J}=7 / 2 \mathrm{P}=0.88 \mathrm{MeV}$.

\section{Further Analysis of Nuclear Level Mass Periods}

Most of the nuclear level mass periods are obtained from [2]. Some others, are shown here, in order to be able to compare mass and width periods of these nuclei. The differences between two successive increasing masses are plotted versus their mean values. 


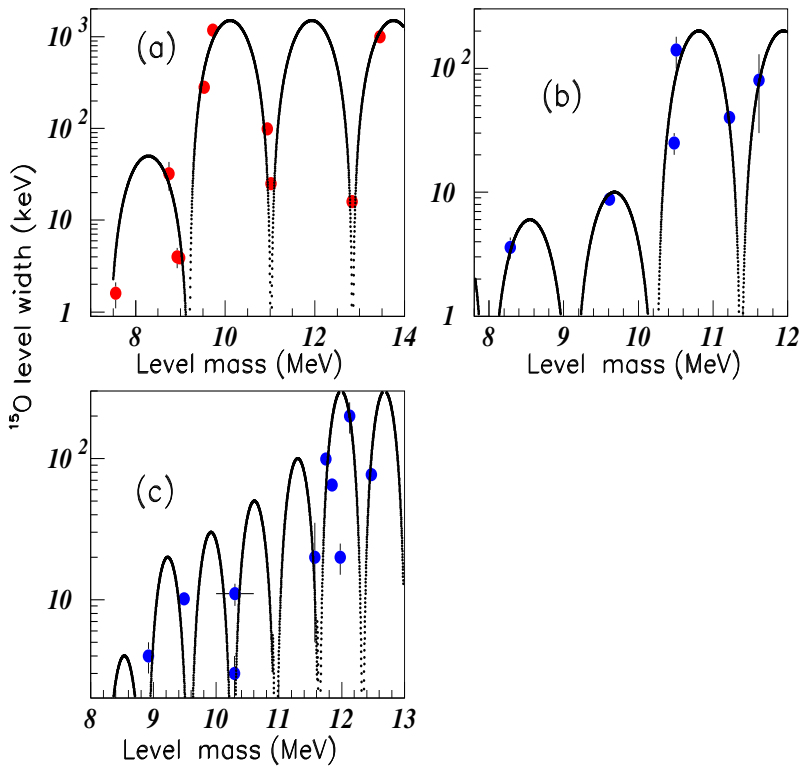

Figure 5. Color on line. Data and fits for ${ }^{15} \mathrm{O}$ nucleus excited state level widths $\mathrm{J}=1 / 2$ in insert (a), $\mathrm{J}=3 / 2$ in insert (b), and $\mathrm{J}=5 / 2$ in insert (c). See text.
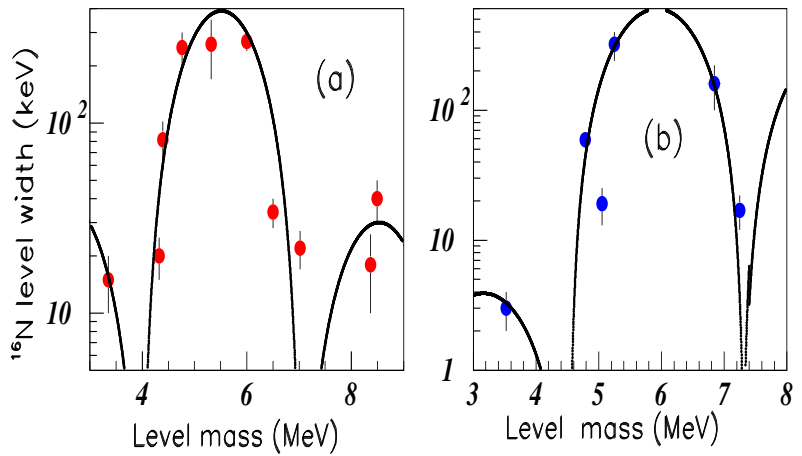

Figure 6. Color on line. Inserts (a) and (b) show data and fits for ${ }^{16} \mathrm{~N}$ nucleus excited state level widths for the spin values respectively $\mathrm{J}=1$ and $\mathrm{J}=2$. See text.

Fig. 15 shows the data and fits for the masses of the ${ }^{40} \mathrm{Ca}$ nucleus levels having respectively the spin values: $\mathrm{J}=2 \mathrm{P}=1.508 \mathrm{MeV}$ and $\mathrm{J}=4 \mathrm{P}=1.10 \mathrm{MeV}$.

Fig. 16 shows the data [6] and fits for ${ }^{17} \mathrm{O}$ (blue stars on line) and ${ }^{17} \mathrm{~F}$ (red circles on line) nuclei excited state masses. Inserts (a), (b), (c), and (d) correspond respectively to $\mathrm{J}=1 / 2 \mathrm{P}=1.445 \mathrm{MeV}, \mathrm{J}=3 / 2$ $\mathrm{P}=1.30 \mathrm{MeV}, \mathrm{J}=5 / 2 \mathrm{P}=1.30 \mathrm{MeV}$, and $\mathrm{J}=7 / 2 \mathrm{P}=1.30 \mathrm{MeV}$. The oscillation amplitudes are larger for the ${ }^{17} \mathrm{~F}$ nucleus than for ${ }^{17} \mathrm{O}$.

Fig. 17 shows the data of the masses of the excited states for the two $\mathrm{A}=41$ nuclei $[6] .{ }^{41} \mathrm{Ca}$ data are shown by red circles and ${ }^{41} \mathrm{Sc}$ data by blue squares. Inserts (a), (b), (c), and (d) correspond relatively to spin levels $\mathrm{J}=1 / 2 \mathrm{P}=2.07 \mathrm{MeV}, \mathrm{J}=3 / 2 \mathrm{P}=2.45 \mathrm{MeV}, \mathrm{J}=5 / 2 \mathrm{P}=1.13 \mathrm{MeV}$, and $\mathrm{J}=7 / 2 \mathrm{P}=1.16 \mathrm{MeV}$. Several dispersed data are observed for the $\mathrm{J}=3 / 2$ levels of the ${ }^{41} \mathrm{Sc}$ nucleus (insert (b)), corresponding to several masses either without known spin, or with several possible spins. In insert (b), the first ${ }^{41} \mathrm{Sc}$ data at $\mathrm{x}=2.75 \mathrm{MeV}$ and $\mathrm{y}=2.06$ is omitted, since out of range, indicating with a large probability the missing of a $\mathrm{J}=3 / 2$ level between $\mathrm{M}=1.718 \mathrm{MeV}$ and $\mathrm{M}=3.774 \mathrm{MeV}$. There is indeed in this range two levels with unknown spin and two levels with several possible spins including $\mathrm{J}=3 / 2$. 

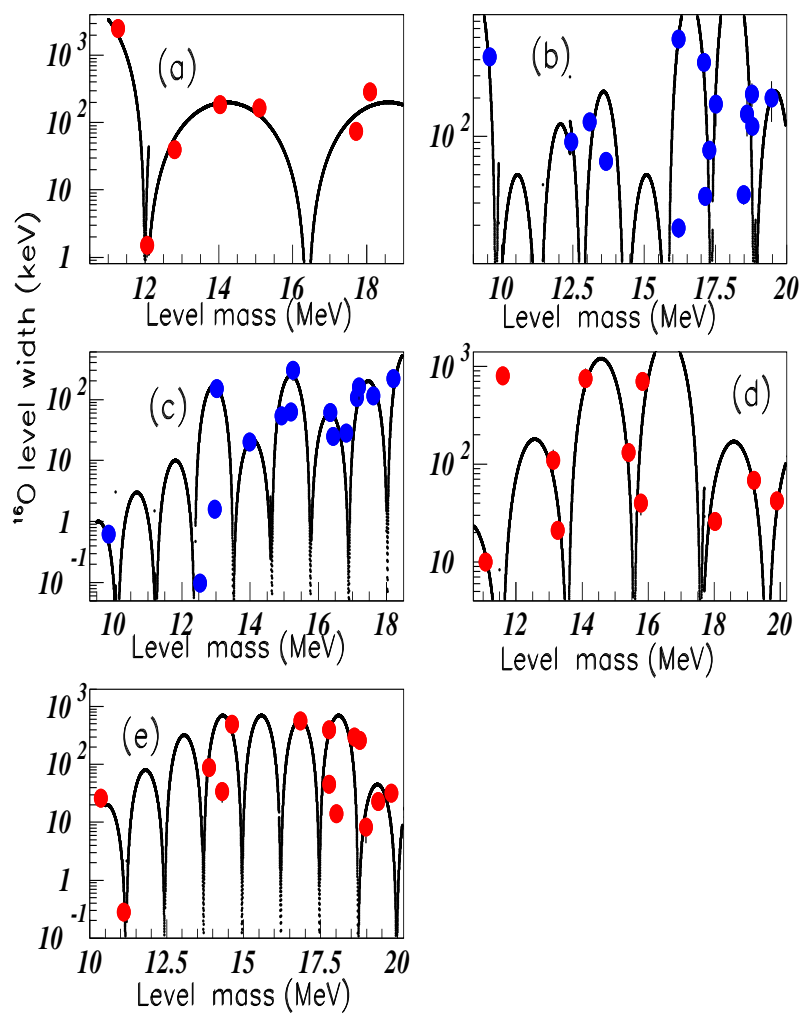

Figure 7. Color on line. Inserts (a), (b), (c), (d), and (e) show the widths data and fits of the excited states of the ${ }^{16} \mathrm{O}$ nucleus, for the spin values $\mathrm{J}=0, \mathrm{~J}=1, \mathrm{~J}=2, \mathrm{~J}=3$, and $\mathrm{J}=4$ respectively. See text.

Fig. 18 shows the data of ${ }^{15} \mathrm{O}$ nucleus excited state level masses [4]. Inserts (a), (b), and (c) correspond respectively to the spin values: $\mathrm{J}=1 / 2 \mathrm{P}=1.26 \mathrm{MeV}, \mathrm{J}=3 / 2 \mathrm{P}=1.26 \mathrm{MeV}$, and $\mathrm{J}=5 / 2 \mathrm{P}=1.07 \mathrm{MeV}$.

Fig. 19 shows the data of masses, analysed as indicated previously, of the excited states of the ${ }^{24} \mathrm{Mg}$ nucleus [6], and corresponding fits. Inserts (a), (b), and (c) correspond to $\mathrm{J}=0 \mathrm{P}=1.90 \mathrm{MeV}, \mathrm{J}=1$ $\mathrm{P}=1.1 \mathrm{MeV}$, and $\mathrm{J}=2 \mathrm{P}=1.92 \mathrm{MeV}$ respectively.

\section{Discussion}

As said previously, in some figures the data close to the maximum studied mass, lie outside the fits. It is to be noticed that we have often, at lower masses, some data without known spin, or rather several possible spins. Therefore it might be possible to attribute the discrepancy between data and fit to the assumption that one (or more) of the 'missing spin' levels must have the studied spin.

The genuine study of the oscillation amplitudes should be done with the help of theoretical studies, outside the scope of the present paper. What follows is an attempt to give some properties of these amplitudes.

Large oscillation width amplitudes require a log scale, while a linear scale is enough for mass oscillation amplitudes.

The values of width and mass periods are collected in tables I and II. Table III shows the width periods (in MeV) for the different spins of the studied nuclei. Table IV shows the mass periods (in $\mathrm{MeV}$ ) for the different spins of the studied nuclei.

We start to compare the mass oscillations of ${ }^{17} \mathrm{~F}$ and ${ }^{17} \mathrm{O}$ nuclei (figs. 14 and 16). The tables show that the level mass periods $\mathrm{P}(\mathrm{m})$ and the level width periods $\mathrm{P}(\mathrm{w})$ are the same for both nuclei for each spin values $\mathrm{J}=1 / 2,3 / 2,5 / 2$, and $7 / 2$. However the level masses are not the same. Therefore we conclude that the oscillating periods of the level mass variations and level width variations, depend merely on the number of nucleons and not on the nuclei charges. 


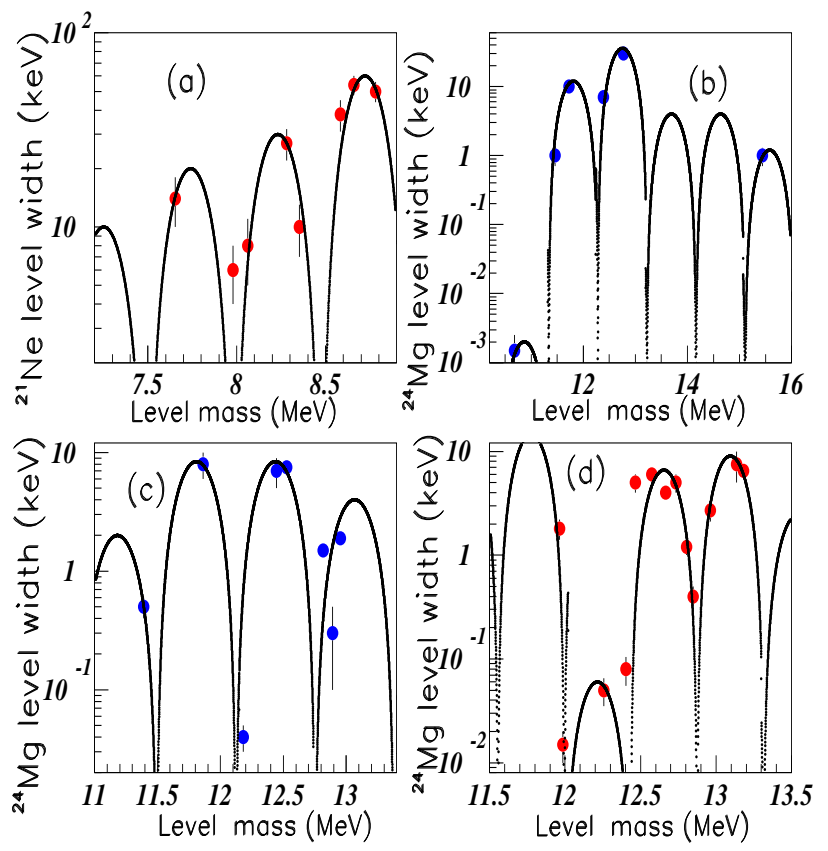

Figure 8. Color on line. Insert (a) shows the width data and fits of the excited states $\mathrm{J}=3 / 2$ of the ${ }^{21} \mathrm{Ne}$ nucleus. Inserts (b), (c), and (d) show the data and fits of the widths of the ${ }^{24} \mathrm{Mg}$ nucleus for $\mathrm{J}=0,1$, and 2 respectively. See text.
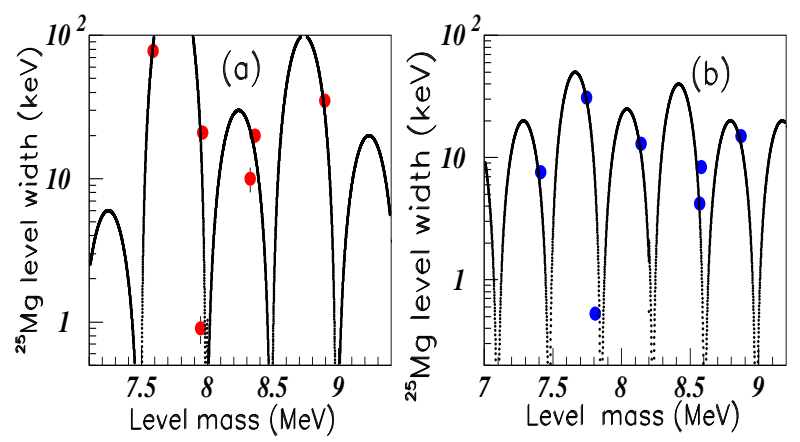

Figure 9. Color on line. Inserts (a) and (b) show the data and fits of the widths of the excited states of the ${ }^{25} \mathrm{Mg}$ nucleus. $\mathrm{J}=1 / 2$ and $\mathrm{J}=3 / 2$ respectively. See text.
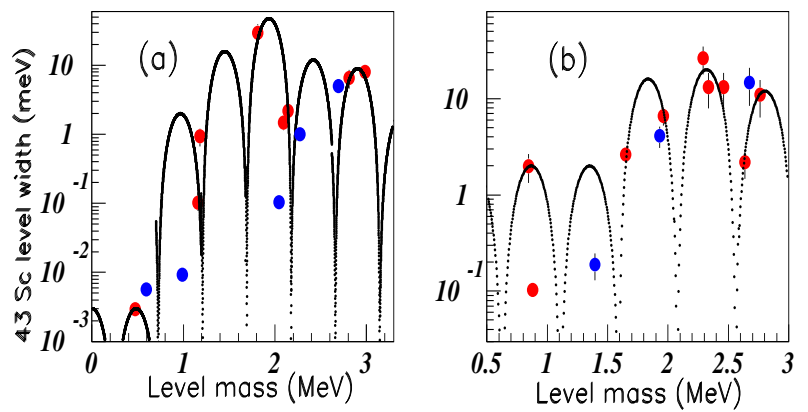

Figure 10. Color on line. Inserts (a) and (b) show the data and fits of the widths of the excited states of the ${ }^{43} \mathrm{Sc}$ and ${ }^{43} \mathrm{Ca}$ nuclei. $\mathrm{J}=3 / 2$ and $\mathrm{J}=5 / 2$ respectively. See text. 

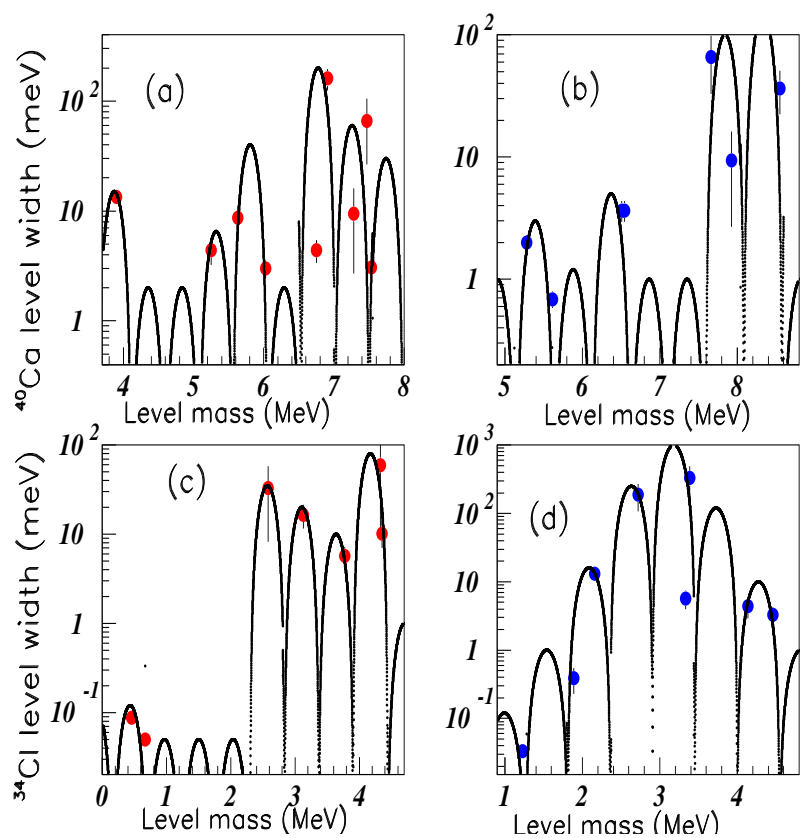

Figure 11. Color on line. Inserts (a) and (b) show the data and fits of the widths of the excited states of the ${ }^{40} \mathrm{Ca}$ nucleus with spin values $\mathrm{J}=2$ and $\mathrm{J}=4$ respectively. Inserts (c) and (d) show the data and fits of the widths of the excited states of the ${ }^{34} \mathrm{Cl}$ nucleus with spin values $\mathrm{J}=1$ and $\mathrm{J}=2$ respectively. See text.

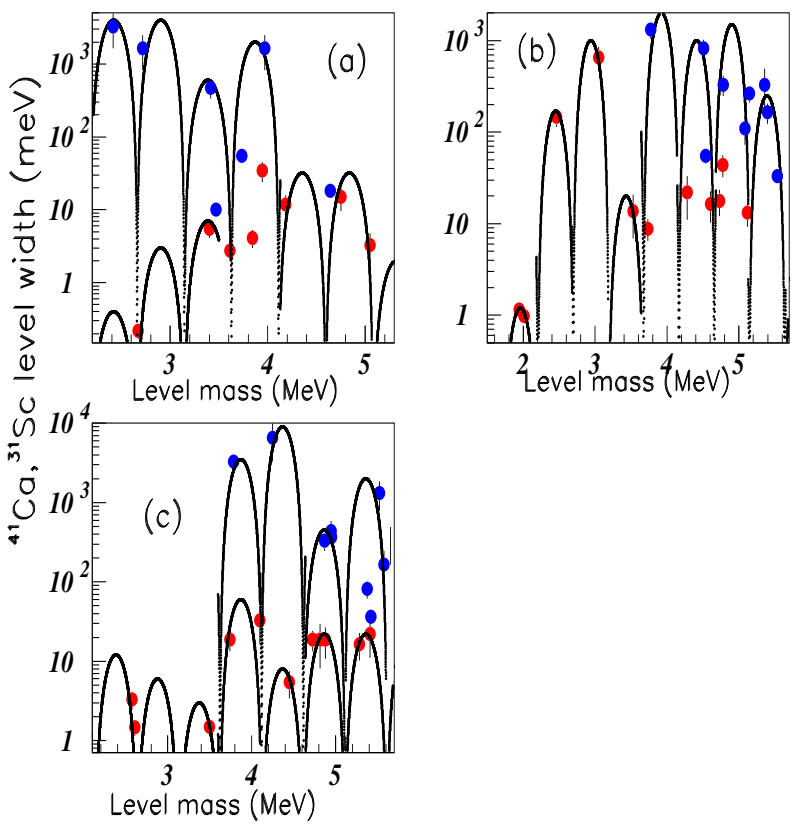

Figure 12. Color on line. Inserts (a), (b), and (c) show the data and fits of the widths of the excited states of the ${ }^{41}$ Ca nucleus with $\mathrm{J}=1 / 2,3 / 2$, and $5 / 2$ respectively. See text. 

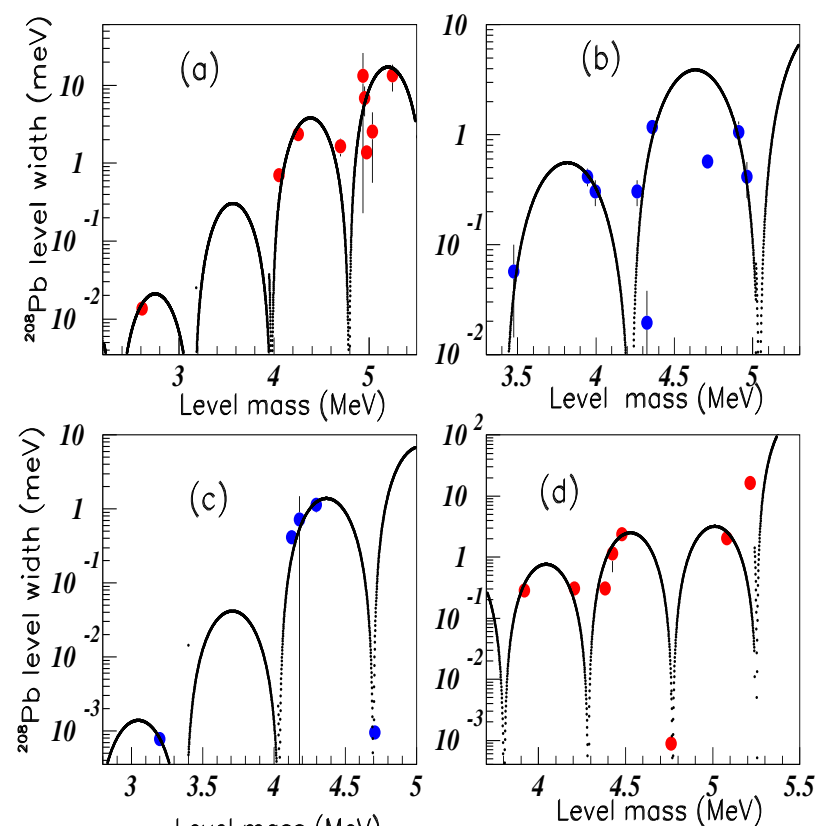

Figure 13. Color on line. Inserts (a), (b), (c), and (d) show the data and fits of the widths of the excited states of the ${ }^{208} \mathrm{~Pb}$ nucleus. $\mathrm{J}=3,4,5$, and 6 respectively. See text.
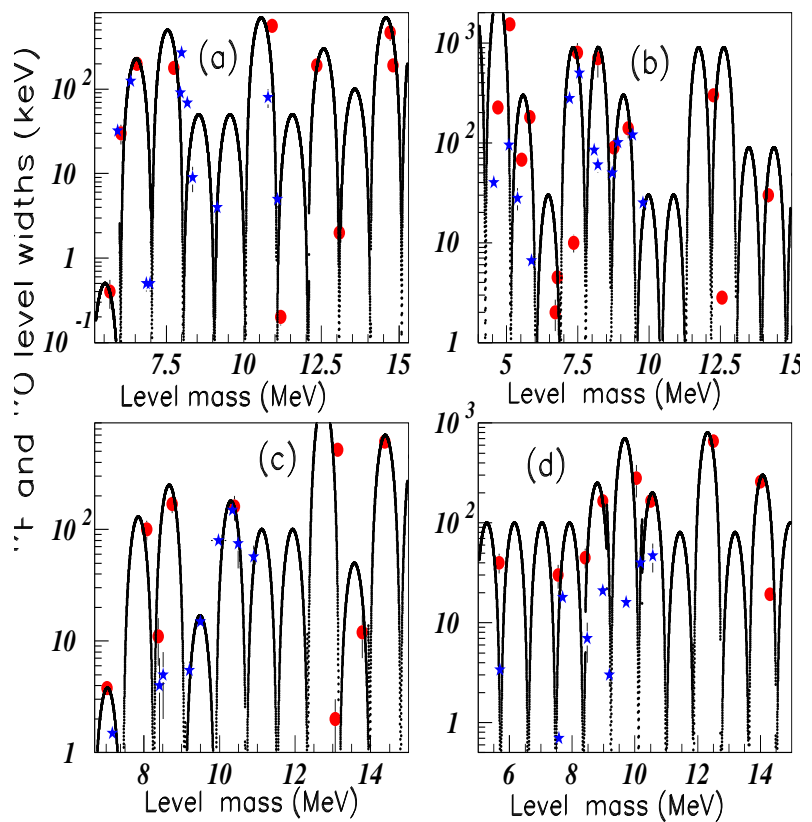

Figure 14. Color on line. Inserts (a), (b), (c), and (d) show the data and fits of the widths of the excited states of the ${ }^{17} \mathrm{O}$ nucleus with spin values $\mathrm{J}=1 / 2,3 / 2,5 / 2$, and $7 / 2$ respectively. See text. 


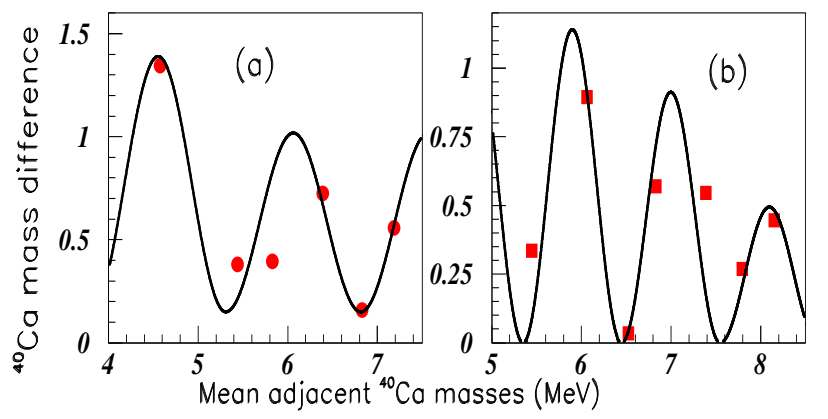

Figure 15. Color on line. Inserts (a) and (b) show the data and fits for the masses of the ${ }^{40} \mathrm{Ca}$ nucleus excited states levels having respectively the spin values: $J=2$ and $J=4$. See text.

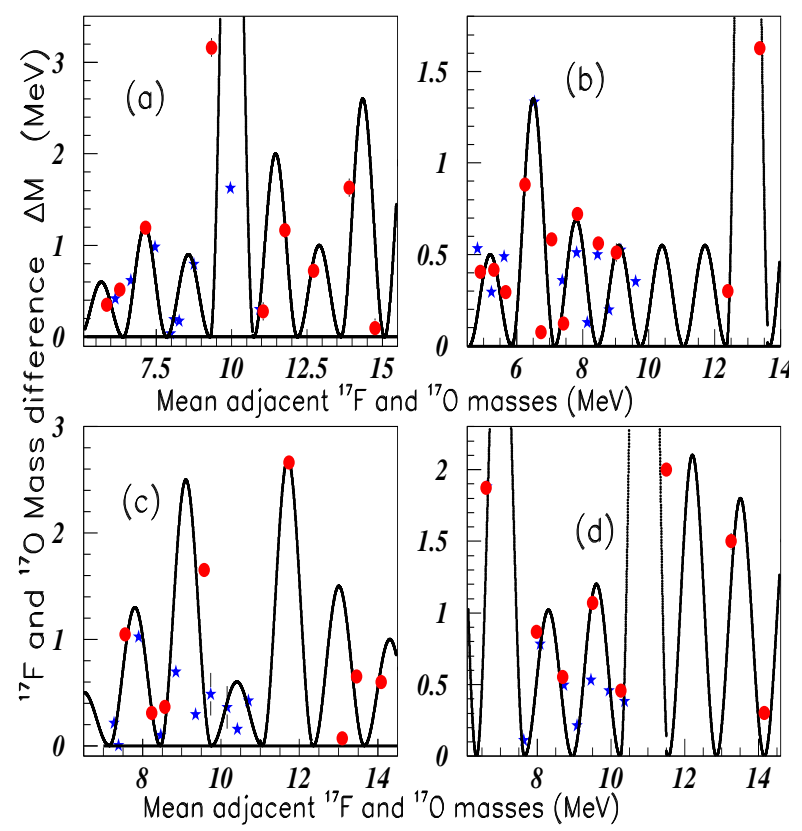

Figure 16. Color on line. Data and fits for ${ }^{17} \mathrm{O}$ (blue stars) and ${ }^{17} \mathrm{~F}$ (red circles) nuclei excited state masses. Inserts (a), (b), (c), and (d) correspond respectively to $\mathrm{J}=1 / 2, \mathrm{~J}=3 / 2, \mathrm{~J}=5 / 2$, and $\mathrm{J}=7 / 2$. See text. 


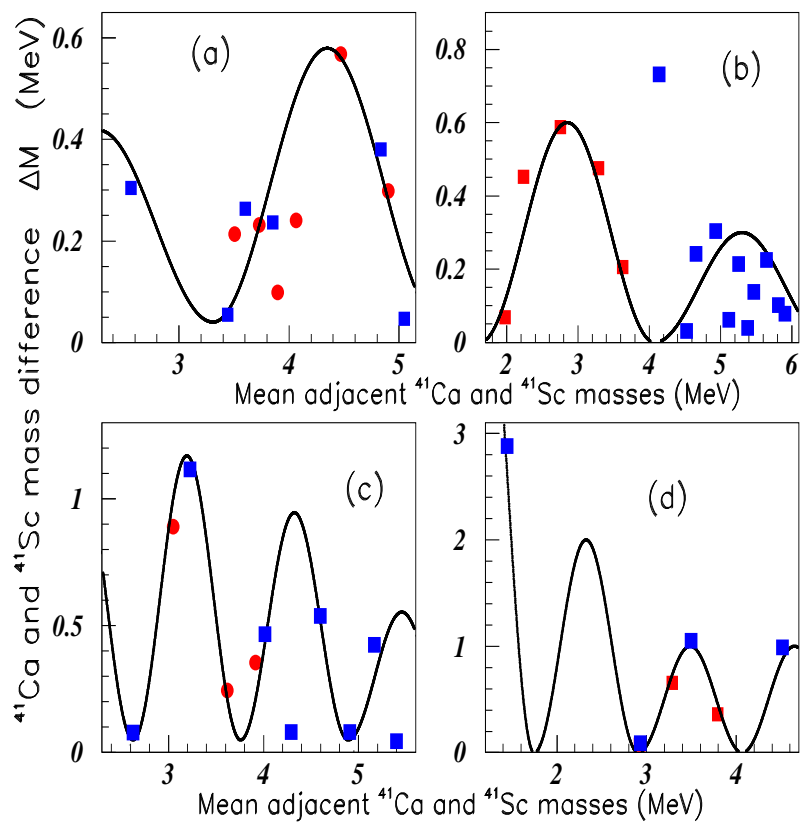

Figure 17. Color on line. Inserts (a), (b), (c), and (d) show data and fits for the masses of the ${ }^{41}$ Ca nuclei excited state levels (red circles) and ${ }^{41} \mathrm{Sc}$ nuclei (blue squares) having respectively the spin values: $\mathrm{J}=1 / 2, \mathrm{~J}=3 / 2, \mathrm{~J}=5 / 2$, and $J=7 / 2$. See text.

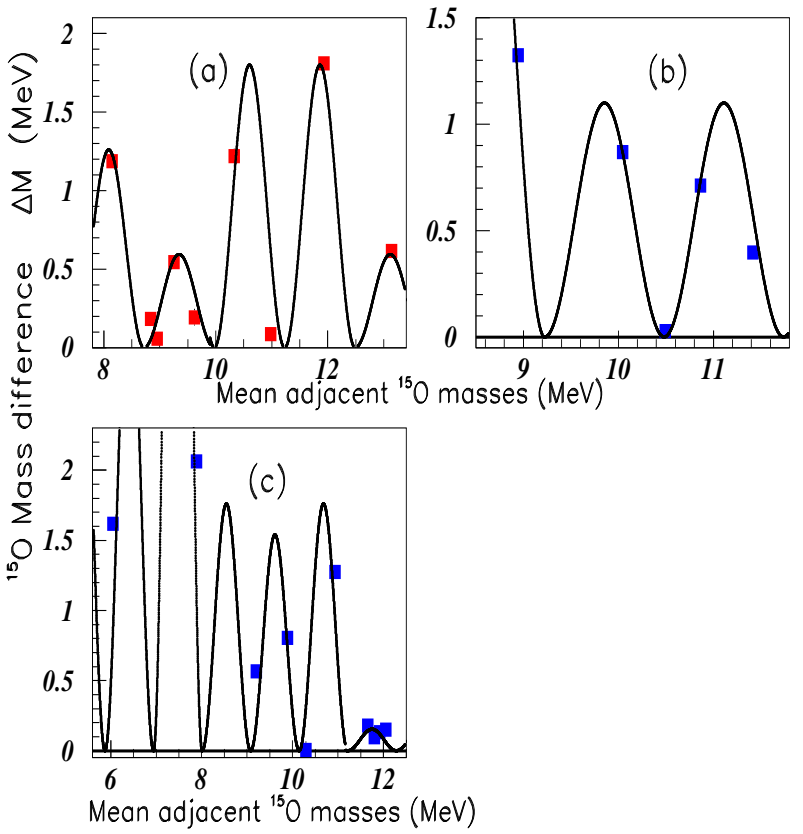

Figure 18. Color on line. Inserts (a), (b), and (c) show data and fits for the masses of the ${ }^{15} \mathrm{O}$ nuclei excited state levels having respectively the spin values: $\mathrm{J}=1 / 2, \mathrm{~J}=3 / 2$, and $\mathrm{J}=5 / 2$. See text. 


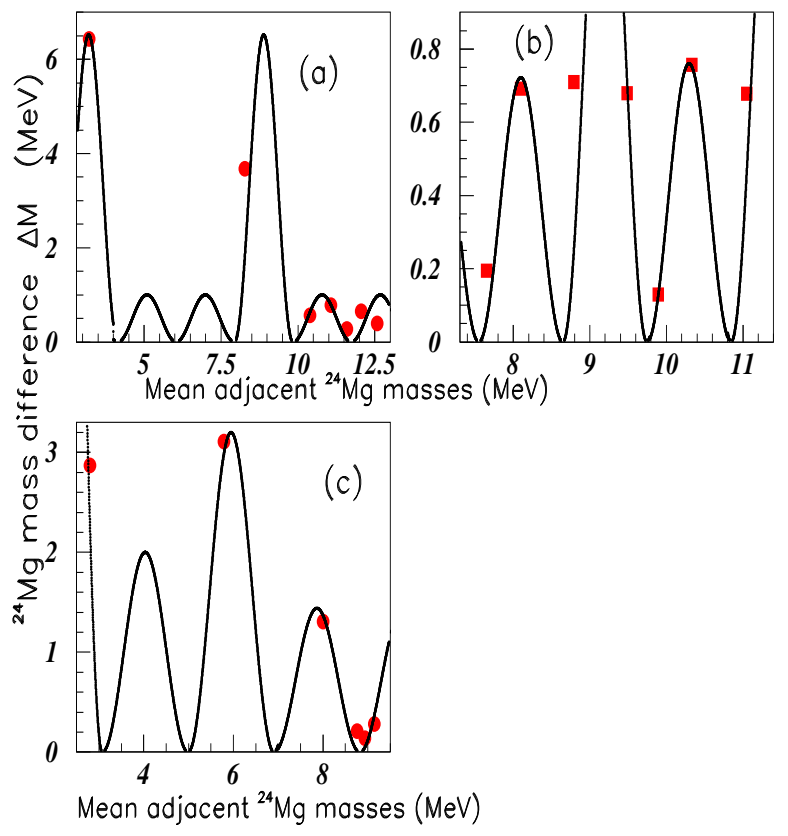

Figure 19. Color on line. Inserts (a), (b), and (c) show the data and fits for the masses of the ${ }^{24} \mathrm{Mg}$ nuclei excited state levels having respectively the spin values: $\mathrm{J}=0, \mathrm{~J}=1$, and $\mathrm{J}=2$. See text. 
The periods decrease from $\mathrm{J}=1 / 2$ to $\mathrm{J}=3 / 2$, and remain more or less constant for higher spins. The rather large period variations, for increasing spins, decrease for increasing nuclei masses.
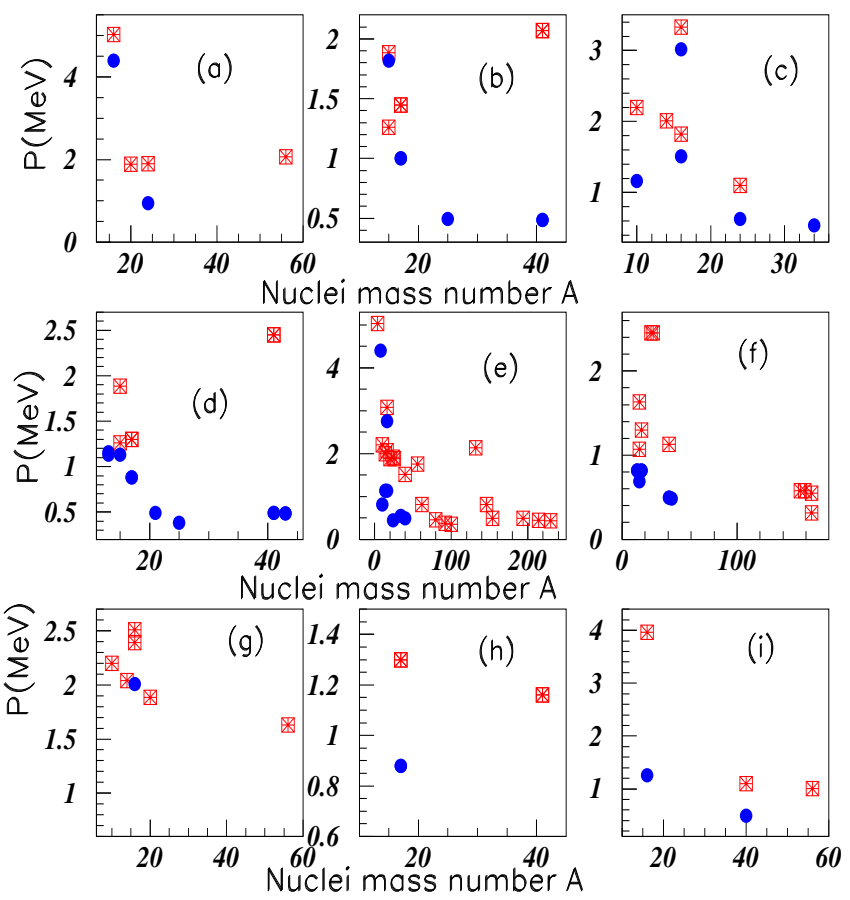

Figure 20. Color on line. Inserts (a), (b), (c), (d), (e), (f), (g), (h), and (i) show successively the periods versus the mass $\mathrm{A}$ of nuclei with spin $\mathrm{J}=0,1 / 2,1,3 / 2,2,5 / 2,3,7 / 2$, and 4 . Red empty squares with crosses are for masses, blue full circles for widths.

The oscillation amplitudes are larger for $\mathrm{Z}=\mathrm{N}+1$ nuclei, than for $\mathrm{Z}=\mathrm{N}-1$ nuclei. This is observed as well in the comparison of ${ }^{17} \mathrm{~F}$ with ${ }^{17} \mathrm{O}$ nuclei, than in the comparison of ${ }^{41} \mathrm{Sc}$ with ${ }^{41} \mathrm{Ca}$ nuclei.

Table III shows the periods (in $\mathrm{MeV}$ ) of the width oscillations of given spin of several nuclei studied above. We observe an oscillation in the ${ }^{16} \mathrm{O}$ row for the five increasing spins. The same tendency exists for $A=17$ nuclei where only four data are available. There is a clear tendency of decreasing periods for low spin increasing masses.

In fig. 20 inserts (a), (b), (c), (d), (e), (f), (g), (h), and (i) show successively the periods versus the mass A of nuclei with spin $\mathrm{J}=0,1 / 2,1,3 / 2,2,5 / 2,3,7 / 2$, and 4 . Red empty squares with crosses show the mass periods obtained in [2] and studied above, blue full circles show the width periods. The data for ${ }^{208} \mathrm{~Pb}$ are omitted in fig. 20 since they will distort the presentation. Several observations are done:

the periods decrease fast for increasing low masses, then remain more or less stable,

the width periods are lower than the mass periods,

the ${ }^{16} \mathrm{~N}$ periods are larger than those of nearby nuclei.

The ${ }^{16} \mathrm{~N}$ width and mass oscillation periods lie above the continuity, by a factor two for $\mathrm{J}=1$ and even larger for $\mathrm{J}=2$, giving rise to a possible missing level(s). A different fit can be obtained with half smaller periods, but as said above, our analyses are performed with the largest possible periods.

The $\mathrm{J}=3 / 2$ width periods are rather stable between ${ }^{21} \mathrm{Ne}$ and ${ }^{43} \mathrm{Sc}$ nuclei (see table I).

Fig. 21 shows the mass and width oscillation periods versus the spin for four nuclei. Inserts (a), (b), (c), and (d) correspond to ${ }^{16} \mathrm{O},{ }^{17} \mathrm{O},{ }^{208} \mathrm{~Pb}$, and ${ }^{41} \mathrm{Ca}$ respectively.

We observe in fig. 21 a more or less proportionality between the variation of mass periods over the width periods, better in insert (b) than in the other inserts. The mean value of these ratios decrease for increasing mass nuclei. 


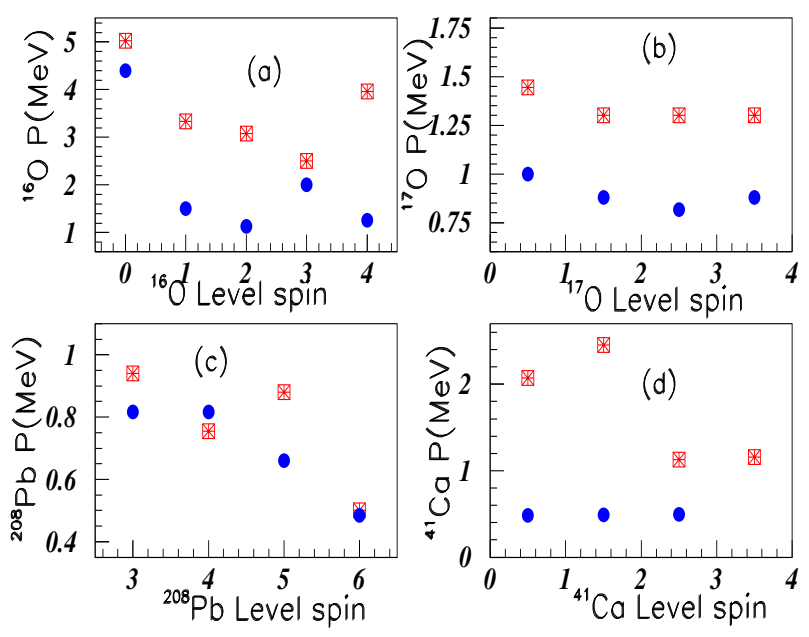

Figure 21. Color on line. Inserts (a), (b), (c), and (d) show successively the mass and width oscillation periods versus the spins of different excited levels for ${ }^{16} \mathrm{O},{ }^{17} \mathrm{O},{ }^{208} \mathrm{~Pb}$, and ${ }^{41} \mathrm{Ca}$ nuclei respectively. Red squares with crosses are for masses, blue full circles for widths.

Fig. 22 shows the ratio of mass periods versus width periods: " $\mathrm{r} "=\mathrm{P}(\mathrm{m}) / \mathrm{P}(\mathrm{w})$, plotted against the level spins J. Black circles describe the " $r$ " values for ${ }^{16} \mathrm{O}$, blue squares describe the " $r$ " values for ${ }^{208} \mathrm{~Pb}$, green up side triangles describe the " $r$ " values for ${ }^{17} \mathrm{O}$ and ${ }^{17} \mathrm{~F}$, and purple down side triangles descibe the "r" values for ${ }^{41} \mathrm{Ca}$. These data are all, except for ${ }^{17} \mathrm{O}$ and ${ }^{17} \mathrm{~F}$ fitted with the same period $\mathrm{P}=2.76 \mathrm{MeV}$ of the periodic oscillation. The data for $A=17$ nucleons are more or less constant, therefore their oscillating period is undertermined. This result of constant " $r$ " connects the mass variation with the width variation of the studied nuclei excited levels.

\section{Conclusion}

A new property of the nuclear level widths is observed, namely that the succession of their widths follows a periodic oscillation, as it was observed previously for masses. The periods of oscillation are studied, but not their amplitudes for which theoretical studies are necessary.

The nuclei excited state masses are better known than the corresponding widths. It seems not possible to use the data shown in figs. 20 and 21 to predict quantitatively some experimentally unknown widths.

The given spin variations, following an oscillatory symmetry, indicate that there is a correlation between the variation of masses and widths of nuclear excited levels. This property is illustrated by the ratio $\mathrm{P}(\mathrm{m}) / \mathrm{P}(\mathrm{w})$.

The study is devoted to static properties of hadrons and nuclei. However dynamic periodic phenomena, oscillating with time, were also observed in different systems. Among others, in chemistry let's quote the Belousov-Zhabotinsky reaction [8] and in "predateur-preys" interactions, the Lotka-Volterra equations [9] applying the Kolmogorov [10] model. These phenomena were discussed in [11]. Such oscillating properties appear to be rather frequent in nature.

\section{References}

1. B. Tatischeff, 'Systematics of oscillatory behavior in hadronic masses and widths', arXiv: 1603.05505v2 [hep-ph] (2016).

2. B. Tatischeff, arXiv:1703.03364v1 [nucl-th] 8 Mar 2017; Journal of Particle Physics 1, 13 (2017).

3. F. Ajzenberg-Selove, Nucl. Phys. A320, 1 (1979).

4. F. Ajzenberg-Selove, Nucl. Phys. A268, 1 (1976).

5. F. Ajzenberg-Selove, Nucl. Phys. A460, 1 (1986).

6. P.M. Endt, and C. Van Der Leun, Nucl. Phys. A310, 1 (1978). 


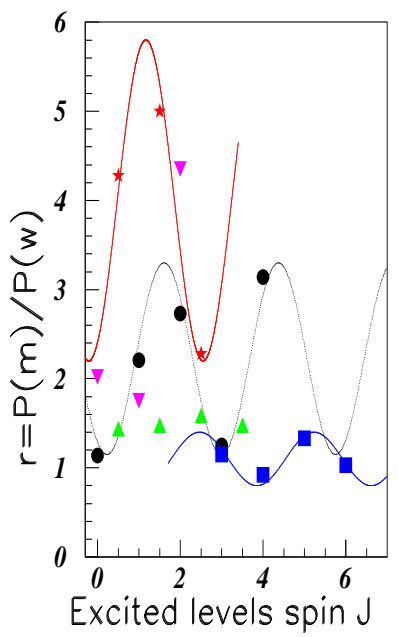

Figure 22. Color on line. The fig. shows the ratio of mass periods versus width periods $" \mathrm{r} "=\mathrm{P}(\mathrm{m}) / \mathrm{P}(\mathrm{w})$ plotted against the level spins J. Black full circles describe the " $r$ " values for ${ }^{16} \mathrm{O}$, blue full squares describe the " $r$ " values for ${ }^{208} \mathrm{~Pb}$, green full up side triangles describe the "r" values for ${ }^{17} \mathrm{O}$ and ${ }^{17} \mathrm{~F}$, and full purple down side triangles descibe the "r" values for ${ }^{41} \mathrm{Ca}$.

7. M.J. Martin, Nuclear Data Sheets 108, 1583 (2007).

8. B.P. Belousov, "Periodically acting reaction and its mechanism". 147: 145 (1959) (in russian). A. M. Zhabotinsky, "Periodical process of oxidation of malonic acid solution." Biophysics. 9: 306-311, (1964) (in russian).

9. A.J. Lotka "Contribution to the Theory of Periodic Reaction", J. Phys. Chem., 14 (3), pp 271-274 (1910).

10. A. Kolmogoroff, "Über die analytischen Methoden in der Wahrscheinlichkeitsrechnung", Math. Ann. 104: 415. doi:10.1007/BF01457949 (1931) (in german).

11. J. de Rosnay, "Je cherche à comprendre...les codes cachés de la nature", editor Les Liens qui Liberent, (2016) (in french). 
Table 1. Quantitative information concerning the oscillation behavior of some nuclei levels, analysed in this paper or analysed previously [2]. $\mathrm{P}(\mathrm{w})$ is the period of the level width oscillations (in $\mathrm{MeV}$ ) and $\mathrm{P}(\mathrm{m}$ ) is the oscillation period of the masses (in $\mathrm{MeV}) . \mathrm{r}=\mathrm{P}(\mathrm{m}) / \mathrm{P}(\mathrm{w})$

\begin{tabular}{|c|c|c|c|c|c|c|}
\hline Spin & nucleus & $\operatorname{fig}[\mathrm{P}(\mathrm{w})]$ & $\mathrm{P}(\mathrm{w})$ & fig $[\mathrm{P}(\mathrm{m})]$ & $\mathrm{P}(\mathrm{m})$ & $\mathrm{r}$ \\
\hline \multirow[t]{4}{*}{0} & ${ }^{16} \mathrm{O}$ & 7 & 4.40 & {$[2]$} & 5.03 & 1.14 \\
\hline & ${ }^{20} \mathrm{Ne}$ & - & - & {$[2]$} & 1.88 & - \\
\hline & ${ }^{24} \mathrm{Mg}$ & 8 & 0.94 & 19 & 1.90 & 2.02 \\
\hline & ${ }^{56} \mathrm{Fe}$ & - & - & {$[2]$} & 2.07 & - \\
\hline \multirow[t]{7}{*}{$1 / 2$} & ${ }^{15} \mathrm{O}$ & 5 & 1.82 & 18 & 1.26 & 0.69 \\
\hline & ${ }^{15} \mathrm{~N}$ & - & - & {$[2]$} & 1.88 & 1.44 \\
\hline & ${ }^{17} \mathrm{O}$ & 14 & 1.01 & 16 & 1.44 & 1.44 \\
\hline & ${ }^{17} \mathrm{~F}$ & 14 & 1.01 & 16 & 1.44 & 1.44 \\
\hline & ${ }^{25} \mathrm{Mg}$ & 9 & 0.50 & - & - & - \\
\hline & ${ }^{41} \mathrm{Ca}$ & 12 & 0.48 & 17 & 2.07 & 4.28 \\
\hline & ${ }^{41} \mathrm{Sc}$ & 12 & 0.48 & 17 & 2.07 & 4.28 \\
\hline \multirow[t]{6}{*}{1} & ${ }^{10} \mathrm{~B}$ & 2 & 1.16 & {$[2]$} & 2.20 & 1.90 \\
\hline & ${ }^{14} \mathrm{~N}$ & - & - & {$[2]$} & 2.01 & - \\
\hline & ${ }^{16} \mathrm{O}$ & 7 & 1.51 & {$[2]$} & 3.33 & 2.21 \\
\hline & ${ }^{16} \mathrm{~N}$ & 6 & 3.02 & {$[2]$} & 1.82 & 0.60 \\
\hline & ${ }^{24} \mathrm{Mg}$ & 8 & 0.63 & 19 & 1.10 & 1.75 \\
\hline & ${ }^{34} \mathrm{Cl}$ & 11 & 0.53 & - & - & - \\
\hline \multirow[t]{12}{*}{$3 / 2$} & ${ }^{13} \mathrm{C}$ & 3 & 1.13 & - & - & - \\
\hline & ${ }^{13} \mathrm{~N}$ & 4 & 1.16 & - & - & - \\
\hline & ${ }^{15} \mathrm{O}$ & 5 & 1.13 & 18 & 1.26 & 1.12 \\
\hline & ${ }^{15} \mathrm{~N}$ & - & - & {$[2]$} & 1.88 & - \\
\hline & ${ }^{17} \mathrm{O}$ & 14 & 0.88 & 16 & 1.30 & 1.48 \\
\hline & ${ }^{17} \mathrm{~F}$ & 14 & 0.88 & 16 & 1.30 & 1.48 \\
\hline & ${ }^{21} \mathrm{Ne}$ & 8 & 0.49 & - & - & - \\
\hline & ${ }^{25} \mathrm{Mg}$ & 9 & 0.38 & - & - & - \\
\hline & ${ }^{41} \mathrm{Ca}$ & 12 & 0.49 & 17 & 2.45 & 5.00 \\
\hline & ${ }^{41} \mathrm{Sc}$ & 12 & 0.49 & 17 & 2.45 & 5.00 \\
\hline & ${ }^{43} \mathrm{Sc}$ & 10 & 0.48 & - & - & - \\
\hline & ${ }^{43} \mathrm{Ca}$ & 10 & 0.48 & - & - & - \\
\hline 2 & ${ }^{4} \mathrm{He}$ & - & - & {$[2]$} & 5.03 & - \\
\hline \multirow[t]{15}{*}{ 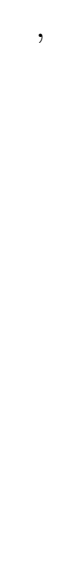 } & ${ }^{8} \mathrm{Be}$ & 1 & 4.40 & - & - & - \\
\hline & ${ }^{10} \mathrm{~B}$ & 2 & 0.82 & {$[2]$} & 2.20 & 2.69 \\
\hline & ${ }^{14} \mathrm{~N}$ & 1 & 1.13 & {$[2]$} & 2.00 & 1.77 \\
\hline & ${ }^{16} \mathrm{O}$ & 7 & 1.13 & {$[2]$} & 3.08 & 2.73 \\
\hline & ${ }^{16} \mathrm{~N}$ & 6 & 2.76 & {$[2]$} & 2.07 & 0.75 \\
\hline & ${ }^{20} \mathrm{Ne}$ & - & - & {$[2]$} & 1.88 & - \\
\hline & ${ }^{24} \mathrm{Mg}$ & 8 & 0.44 & 19 & 1.92 & 4.35 \\
\hline & ${ }^{26} \mathrm{Mg}$ & - & - & {$[2]$} & 1.88 & - \\
\hline & ${ }^{34} \mathrm{Cl}$ & 11 & 0.55 & - & - & - \\
\hline & ${ }^{40} \mathrm{Ca}$ & 11 & 0.48 & 15 & 1.51 & 3.12 \\
\hline & ${ }^{56} \mathrm{Fe}$ & - & - & {$[2]$} & 1.76 & - \\
\hline & ${ }^{62} \mathrm{Zn}$ & - & - & {$[2]$} & 0.82 & - \\
\hline & ${ }^{80} \mathrm{Se}$ & - & - & {$[2]$} & 0.45 & - \\
\hline & ${ }^{92} \mathrm{Nb}$ & - & - & {$[2]$} & 0.38 & - \\
\hline & ${ }^{100} \mathrm{Ru}$ & - & - & {$[2]$} & 0.35 & - \\
\hline
\end{tabular}


Table 2. Table I continuation

\begin{tabular}{|c|c|c|c|c|c|c|}
\hline Spin & nucleus & fig $[\mathrm{P}(\mathrm{w})]$ & $\mathrm{P}(\mathrm{w})$ & fig $[\mathrm{P}(\mathrm{m})]$ & $\mathrm{P}(\mathrm{m})$ & $\mathrm{r}$ \\
\hline \multirow[t]{6}{*}{2} & ${ }^{132} \mathrm{Ce}$ & - & - & {$[2]$} & 2.14 & - \\
\hline & ${ }^{146} \mathrm{La}$ & - & - & {$[2]$} & 0.82 & - \\
\hline & ${ }^{154} \mathrm{Gd}$ & - & - & {$[2]$} & 0.49 & - \\
\hline & ${ }^{194} \mathrm{Pt}$ & - & - & {$[2]$} & 0.49 & - \\
\hline & ${ }^{214} \mathrm{Po}$ & - & - & {$[2]$} & 0.45 & - \\
\hline & ${ }^{230} \mathrm{Th}$ & - & - & [2] & 0.43 & - \\
\hline $5 / 2$ & ${ }^{13} \mathrm{C}$ & 3 & 0.82 & - & - & - \\
\hline \multirow{15}{*}{, } & ${ }^{13} \mathrm{~N}$ & 4 & 0.82 & - & - & - \\
\hline & ${ }^{15} \mathrm{O}$ & 5 & 0.69 & 18 & 1.07 & 1.55 \\
\hline & ${ }^{15} \mathrm{~N}$ & - & - & {$[2]$} & 1.63 & - \\
\hline & ${ }^{17} \mathrm{O}$ & 14 & 0.82 & 16 & 1.30 & 1.59 \\
\hline & ${ }^{17} \mathrm{~F}$ & 14 & 0.82 & 16 & 1.30 & 1.59 \\
\hline & ${ }^{25} \mathrm{Al}$ & - & - & {$[2]$} & 2.45 & - \\
\hline & ${ }^{27} \mathrm{Al}$ & - & - & {$[2]$} & 2.45 & - \\
\hline & ${ }^{41} \mathrm{Ca}$ & 12 & 0.50 & 17 & 1.13 & 2.28 \\
\hline & ${ }^{41} \mathrm{Sc}$ & 12 & 0.50 & 17 & 1.13 & 2.28 \\
\hline & ${ }^{43} \mathrm{Sc}$ & 10 & 0.48 & - & - & - \\
\hline & ${ }^{43} \mathrm{Ca}$ & 10 & 0.48 & - & - & - \\
\hline & ${ }^{155} \mathrm{~Tb}$ & - & - & {$[2]$} & 0.57 & - \\
\hline & ${ }^{159} \mathrm{~Tb}$ & - & - & {$[2]$} & 0.57 & - \\
\hline & ${ }^{165}$ Dy & - & - & {$[2]$} & 0.55 & - \\
\hline & ${ }^{165} \mathrm{Er}$ & - & - & {$[2]$} & 0.31 & - \\
\hline \multirow[t]{7}{*}{3} & ${ }^{10} \mathrm{~B}$ & - & - & [2] & 2.2 & - \\
\hline & ${ }^{14} \mathrm{~N}$ & - & - & {$[2]$} & 2.04 & - \\
\hline & ${ }^{16} \mathrm{O}$ & 7 & 2.01 & {$[2]$} & 2.51 & 1.25 \\
\hline & ${ }^{16} \mathrm{~N}$ & - & - & {$[2]$} & 2.39 & - \\
\hline & ${ }^{20} \mathrm{Ne}$ & - & - & {$[2]$} & 1.88 & - \\
\hline & ${ }^{56} \mathrm{Fe}$ & - & - & {$[2]$} & 1.63 & - \\
\hline & ${ }^{208} \mathrm{~Pb}$ & 13 & 0.82 & [2] & 0.94 & 1.15 \\
\hline \multirow[t]{4}{*}{$7 / 2$} & ${ }^{17} \mathrm{O}$ & 14 & 0.88 & 16 & 1.30 & 1.48 \\
\hline & ${ }^{17} \mathrm{~F}$ & 14 & 0.88 & 16 & 1.30 & 1.48 \\
\hline & ${ }^{41} \mathrm{Ca}$ & - & - & 17 & 1.16 & - \\
\hline & ${ }^{41} \mathrm{Sc}$ & - & - & 17 & 1.16 & - \\
\hline \multirow[t]{4}{*}{4} & ${ }^{16} \mathrm{O}$ & 7 & 1.26 & {$[2]$} & 3.96 & 3.14 \\
\hline & ${ }^{40} \mathrm{Ca}$ & 11 & 0.49 & 15 & 1.10 & 2.24 \\
\hline & ${ }^{56} \mathrm{Fe}$ & - & - & {$[2]$} & 1.00 & - \\
\hline & ${ }^{208} \mathrm{~Pb}$ & 13 & 0.82 & {$[2]$} & 0.75 & 0.92 \\
\hline 5 & ${ }^{208} \mathrm{~Pb}$ & 13 & 0.66 & {$[2]$} & 0.88 & 1.33 \\
\hline 6 & ${ }^{208} \mathrm{~Pb}$ & 13 & 0.48 & {$[2]$} & 0.50 & 1.03 \\
\hline
\end{tabular}


Table 3. Periods (in $\mathrm{MeV}$ ) of the width ocillations of given spins of several nuclei.

\begin{tabular}{cccccccccc}
\hline Spin & $\mathrm{J}=0$ & $1 / 2$ & 1 & $3 / 2$ & 2 & $5 / 2$ & 3 & $7 / 2$ & 4 \\
\hline${ }^{8} \mathrm{Be}$ & & & & & 1.00 & & & & \\
${ }^{10} \mathrm{~B}$ & & & 1.16 & & 0.82 & & & & \\
${ }^{13} \mathrm{C}$ & & & & 1.13 & & 0.82 & & & \\
${ }^{13} \mathrm{~N}$ & & & & 1.16 & & 0.82 & & & \\
${ }^{14} \mathrm{~N}$ & & & & & 1.13 & & & & \\
${ }^{15} \mathrm{O}$ & & 1.82 & & 1.13 & & 0.70 & & & \\
${ }^{16} \mathrm{O}$ & 4.40 & & 1.51 & & 1.13 & & 2.01 & & \\
${ }^{16} \mathrm{~N}$ & & & 3.02 & & 2.76 & & & & \\
${ }^{17} \mathrm{O}$ & & 1.01 & & 0.88 & & 0.82 & & 0.88 & \\
${ }^{17} \mathrm{~F}$ & & 1.01 & & 0.88 & & 0.82 & & & \\
${ }^{21} \mathrm{Ne}$ & & & & 0.49 & & & & \\
${ }^{24} \mathrm{Mg}$ & 0.94 & & 0.63 & & 0.44 & & & \\
${ }^{25} \mathrm{Mg}$ & & 0.50 & & 0.38 & & & & \\
${ }^{34} \mathrm{Cl}$ & & & 0.53 & & 0.55 & & & \\
${ }^{40} \mathrm{Ca}$ & & & & & 0.48 & & & \\
${ }^{41} \mathrm{Ca}$ & & 0.48 & & 0.49 & & & & \\
${ }^{41} \mathrm{Sc}$ & & 0.48 & & 0.49 & & & & \\
${ }^{43} \mathrm{Sc}$ & & & & 0.48 & & 0.48 & & \\
${ }^{43} \mathrm{Ca}$ & & & & 0.48 & & 0.48 & & \\
${ }^{208} \mathrm{~Pb}$ & & & & & & 0.82 & & \\
\hline
\end{tabular}


Table 4. Periods (in $\mathrm{MeV}$ ) of the mass ocillations of given spins of several nuclei.

\begin{tabular}{|c|c|c|c|c|c|c|c|c|c|}
\hline Spin & $\mathrm{J}=0$ & $1 / 2$ & 1 & $3 / 2$ & 2 & $5 / 2$ & 3 & $7 / 2$ & 4 \\
\hline${ }^{4} \mathrm{He}$ & & & & & 5.03 & & & & \\
\hline${ }^{10} \mathrm{~B}$ & & & 2.20 & & 2.20 & & & & \\
\hline${ }^{14} \mathrm{~N}$ & & & 2.01 & & 2.00 & & & & \\
\hline${ }^{15} \mathrm{O}$ & & 1.26 & & 1.26 & & 1.07 & & & \\
\hline${ }^{15} \mathrm{~N}$ & & & & 1.88 & & 1.63 & & & \\
\hline${ }^{16} \mathrm{O}$ & & & 3.33 & & 3.08 & & 2.51 & & 3.96 \\
\hline${ }^{16} \mathrm{~N}$ & & & 1.82 & & 2.07 & & 2.39 & & \\
\hline${ }^{17} \mathrm{O}$ & & 1.44 & & 1.30 & & 1.30 & & 1.30 & \\
\hline${ }^{17} \mathrm{~F}$ & & 1.44 & & 1.30 & & 1.30 & & 1.30 & \\
\hline${ }^{20} \mathrm{Ne}$ & 1.88 & & & & 1.88 & & 1.88 & & \\
\hline${ }^{24} \mathrm{Mg}$ & 1.90 & & 1.10 & & 1.92 & & & & \\
\hline${ }^{25} \mathrm{Al}$ & & & & & & 2.45 & & & \\
\hline${ }^{26} \mathrm{Mg}$ & & & & & 1.88 & & & & \\
\hline${ }^{40} \mathrm{Ca}$ & & & & & 1.51 & & & & 1.10 \\
\hline${ }^{41} \mathrm{Ca}$ & & 2.07 & & 2.45 & & 1.13 & & 1.16 & \\
\hline${ }^{41} \mathrm{Sc}$ & & 2.07 & & 2.45 & & 1.13 & & & \\
\hline${ }^{56} \mathrm{Fe}$ & & & & & 1.76 & & 1.63 & & 1.00 \\
\hline${ }^{62} \mathrm{Zn}$ & & & & & 0.82 & & & & \\
\hline${ }^{80} \mathrm{Se}$ & & & & & 0.45 & & & & \\
\hline${ }^{92} \mathrm{Nb}$ & & & & & 0.38 & & & & \\
\hline${ }^{100} \mathrm{Ru}$ & & & & & 0.35 & & & & \\
\hline${ }^{132} \mathrm{Ce}$ & & & & & 2.14 & & & & \\
\hline${ }^{146} \mathrm{La}$ & & & & & 0.82 & & & & \\
\hline${ }^{154} \mathrm{Ga}$ & & & & & 0.49 & & & & \\
\hline${ }^{155} \mathrm{~Tb}$ & & & & & & 0.57 & & & \\
\hline${ }^{159} \mathrm{~Tb}$ & & & & & & 0.57 & & & \\
\hline${ }^{165} \mathrm{Dy}$ & & & & & & 0.55 & & & \\
\hline${ }^{165} \mathrm{Er}$ & & & & & & 0.31 & & & \\
\hline${ }^{194} \mathrm{Pt}$ & & & & & 0.49 & & & & \\
\hline${ }^{208} \mathrm{~Pb}$ & & & & & & & 0.94 & & 0.75 \\
\hline${ }^{214} \mathrm{Po}$ & & & & & 0.45 & & & & \\
\hline${ }^{230} \mathrm{Th}$ & & & & & 0.43 & & & & \\
\hline
\end{tabular}

